\title{
ACUTE GLAUCOMA: AN HISTORICAL NOTE
}

BY

\author{
ARNOLD SORSBY
}

LON DON

WHILST the term glaucoma goes back to the Hippocratic writings, the conception of acute glaucoma is barely more than a 100 years old. It is true that descriptions suggestive of the affection are found in early writings. Thus Hirschberg ${ }^{1}$ draws attention to passages in Tabari, and Benevenutus and particularly to the significant passage in Sams-addin :

"Migraine of the eye, also known as Headache of the pupil. This is a pain situated deep in the eye stabbing or pressing or both: sometimes constant, sometimes transient. It is caused by retained matter in the vessels of the retina. The aforementioned pain is its sign. Hemicrania precedes it or is associated with it. Dullness of the fluids is always present. Sometimes cataract develops from it and also dilatation of the pupil. If it becomes chronic, tenseness of the eye follows and vision is feeble. Treatment : bleeding and purgation. Instilling white of egg and milk ; sometimes drugging for the pain is necessary."

Sams-addin's attempt at differential diagnosis within the group of lesions passing under the name of ophthalmia had no far-reaching consequences, and glaucoma itself remained a vague conception for irremediable blindness in which the pupil had a bluish or greenish discolouration. Indeed glaucoma was essentially hopelessly incurable blindness for in the medical philosophy of Galen which held sway till the Renaissance, glaucoma was dryness and shrinking of the crystalline (lens), itself the seat of vision. The reorientation that resulted, in the first place from the work of the XVIIth century anatomists and physiologists, especially of Keppler and Schreiner in showing the retina as the organ of sight, and secondly from the conclusive evidence of Brisseau in 1709 that it is the lens that is affected in cataract and not a space in front of it, demanded a new conception for the pathology of glaucoma. Never a very definite clinical entity, it passed through a period of exceptional vagueness during the whole of the XVIIIth century and it is only towards the beginning of the XIXth century that glaucoma commences to re-assert itself. It is significant that in its re-emergence it is a clinical entity which is first recognized-. under a multitude of different names-and only later is it recognized as glaucoma. The essential unity of acute and chronic glaucoma comes later still, and only after the unfortunate name had lost all its original significance and had become a mere label. 
During the XVIIIth century and for nearly half of the XIXth century glaucoma remained a descriptive term for that phase of ocular inflammation in which the pupil assumes a greenish hue. Tentative attempts at the recognition of what we know now as acute glaucoma were made as early as 1722 , when St. Yves ${ }^{2}$ described an acute condition in which blindness with an unobscured pupil supervenes followed afterwards by glaucoma.

"La goutte sereine suit cette fluxion après laquelle succède un glaucome."

The anonymous author (?John Hill) of the Fabrick of the eye and the several disorders which obstruct the sight. London, $1758,{ }^{3}$ gave an account in which glaucoma is divided into three stages, of which the first is an unconvincing description, and the second and third stages indicative of absolute glaucoma with its acute symptoms.

Under the name of glaucoma Arachart ${ }^{4}$ in 1786 describes acute conditions in which there is varying degree of greenish hue; perfect glaucoma is present when there is complete blindness and the pupil is greenish-yellow, approaching the colour of a dead oakleaf; imperfect-when there is still some vision and the pupil has a whitish-greenish colour.

It is not until 1813 that a really convincing description of acute glaucoma appears-an account by Joseph Beer. ${ }^{5}$. A form of iritis is differentiated from other varieties by its distinctive symptoms and in that it ends in blindness, a greenish hue (glaucoma), a dilated pupil and cataract-a passable description of absolute glaucoma. In his ambitious attempt to describe eye diseases on a basis of causation he named this acute eye condition iritis of gouty origin.

A most excellent description is given in 1818 by A. P. Demours. ${ }^{6}$. Rainbow colours and hardness of the eye are mentioned and the condition is named glaucoma. An even fuller account is given by Weller ${ }^{7}$ who combines the descriptions of both Beer and Demours. He retains both terms-arthritic iritis (and ophthalmitis) and glaucoma, apparently as separate clinical entities, discussed in different parts of the book; the same condition seems to have been regarded as arthritic ophthalmitis when there was no greenish pupil reflex and glaucoma when such was present.

In this connection it is worth noting that whilst a strong resemblance between acute iritis and acute glaucoma was tacitly admitted in the name of arthritic iritis, the various synonyms suggested such as arthritic ophthalmitis, (Benedict, Rosas) arthritic inflammation of the internal tunics (Lawrence, Wharton Jones), show that a realization of some fundamental difference between the two conditions was gradually being achieved. How difficult that must have been, before the full appreciation of the significance of hyper- 
for this variety of iritis being much less amenable to antiphlogistic treatment than the others.

2. Changes in the iris and pupil. Beer has described these F Smuju (Now as varying in two different habits of body. In those who are layp of a meagre and irritable habit, and tense fibre the pupil contracts, is filled with effused lymph, and becomes adherent to the capsule, as is generally the case in the other species of iritis. In such cases, the only characteristic symptom, besides the white ring round the cornea, is a varicose state of the blood vessels of the iris, so that after the disease has fully developed itself, they may be discerned ramifying on the surface of that membrane, or forming a vascular wreath within the verge of the contracted pupil. Before it arrives at this stage, the inflammation is always attended with general fever. If the eye is left to itself, it does not suppurate, but its contents begin to be absorbed, and at last its volume is extremely

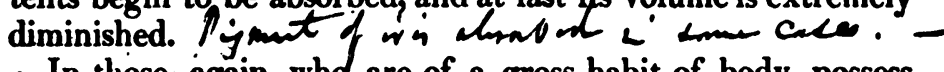
In Ihose, agoim whd are of a gross habit of body, possess little sensibility, and have a lax fibre, the iris instead of expanding, contracts remarkably, a sign of attending amaurosis, and at the same time loses its motion and natural black colour. $\ngtr$ The pupil is not always dilated uniformly along its whole circumference; not unfrequently the iris contracts more towards the temporal and nasal sides of the eye, so that the pupil assumes an oval shape; indeed, the iris sometimes becomes so narrow on the two sides mentioned, especially on the temporal, as almost to disappear. Along with these changes, there is no effusion of lymph, nor any abscess on the surface of the iris. \& Behind the enlarged pupil, there is perceived the greyish-green reflection, characteristic of glaucoma, a state of the eye depending on absorption of the pigmentum nigrum, with dissolution of the vitreous humour, and occasionally accompanied by discolouration of the lens. After a time, the lens is plainly seen to have lost its trans(hat parency, and to have assumed an opaque sea-green colour; the anterior chamber. + The iris, lying upon the enlarged lens, $6.1 \mathrm{f}$ seems much altered from its natural texture; it looks soft, and cormen as if it had undergone a degree of maceration. The varicose state of the vessels of the conjunctiva increases, while those of the choroid becoming similarly affected, form bluish knots, which shine through the sclerotica. The anterior part of this tunic being extenuated by the pressure of the morbid parts within, a dark ring shines through it, exactly occupying the

PAGF from the first edition of William Mackenzie's Practical Treatise of the Diseases of the Eye, London, 1830, with his marginal notes for additions to the second edition.

In speaking of arthritic iritis he states: "The general symptoms of iritis are present in the arthritic species, namely, zonular sclerotitis, discolouration of the iris, turbidness of the pupil. with changes in its shape, size and mobility, impaired vision and pain in and around the eye. These symptoms are, however, modified in such a manner as to afford a ready diagnosis.'

This reproduced page with its reference to Acute Glaucoma of Lawrence deals, as can be seen, with the diagnostic features in the changes in the iris and pupil.

"Middleton's case, March, 1883," probably refers to a patient of that name. 
tension, can be imagined from the difficulty in diagnosis that cases of subacute glaucoma may present to-day.

The first to realize the connection between arthritic ophthalmitis and glaucoma seems to have been Sir William Lawrence. His work on glaucoma has received no consideration from historians, yet it is of sufficient merit to add lustre even to his name. In the lectures delivered at the London Ophthalmic Infirmary and published in the Lancet for 1826, he, like Weller, describes arthritic ophthalmitis and glaucoma as separate conditions, giving under the one a good account of acute glaucoma, mentioning hardness of eye as one of the symptoms, and under the other an account of chronic glaucoma, in which the cardinal sign, increased hardness, is missing.

In speaking of deep seated acute inflammation of the eye he follows a current conception in distinguishing ophthalmitis arthritica from idiopathic ophthalmitis: Ophthalmitis arthritica "ends in a dilated pupil, that is the appearance called glaucoma ; it might be called in contradistinction to the slowly, occurring change of similar character which will be afterwards described, acute glaucoma. Benedict has named it, in consequence of its frequent occurrence in gouty persons, ophthalmitis arthritica." "8 In discussing glaucoma (i.e., blindness with a greenish pupil) he again brings out its association with arthritic ophthalmitis.

"With respect to the causes of this affection, we can point out nothing peculiar as contributing to its occurrence. It takes place at or after the middle period of life, and in persons not of the most healthy character. It appears to me to be merely a chronic form of the same inflammation which I have described to you as the arthritic inflammation affecting the posterior coats of the eye : the changes which occur in the retina, vitreous humour and lens, as the consequences of that inflammation, are rapid and sudden, whilst in the present case the disease has a slower progress, and the changes are more slowly produced; but it certainly does appear to occur more frequently in such persons as are liable to gout and rheumatism than in others. It is of considerable importance that you should be well aware of the characteristics of this affection, since it is liable to be mistaken for cataract." 9.

In lectures delivered at St. Bartholomew's Hospital, eye diseases are dealt with less fully. As reported in the Lancet for 1830, in speaking of acute inflammation of the vitreous humour, retina and choroid (i.e., the "internal tunics" of the earlier lecture) he stated: "These occur in elderly persons, at all events in persons past the middle period of life ; severe pains will come in the eye, the pupil becomes dilated and instead of presenting its natural colour, exhibits a dull dirty greenish hue, in consequence of the change which the inflamed vitreous humour has undergone. With 
this green shade, this excessively dilated condition of the pupil and the dull leaden looking iris, you have almost a complete loss of vision. It is in fact, an inflammation commencing in parts most essential to the function of vision in the retina, in the vitreous humour and probably involving the choroid coat. It has sometimes been called Acute Glaucoma, this term being derived from the greenish appearance of the eye. It has been called glaucoma from another symptom which takes place where, without any enlargements of the vessels, without any very severe pain or absolute extinction of vision in the first place, the pupil exhibits the same greenish discolouration. You can only see it by standing directly before the patient, not by looking at the eye sideways. This is called glaucoma simply, and it appears to me to be a chronic form of the same affection as to that to which the term acute glaucoma is given." 10 .

In no writer at that period is the recognition of the identity between arthritic ophthalmitis and glaucoma to be found-the general conception being that glaucoma is a condition which may supervene on some cases of arthritic ophthalmitis. Lawrence saw further than this, and though the credit for introducing the term acute glaucoma must be given to him, it must be recognized that in linking up arthritic ophthalmitis and acute glaucoma he did so not on the basis of the modern conception of glaucoma, but on the elusive greenish discolouration.

It must further be admitted that in spite of his deep insight into the problem he did not grasp the whole position. In common with his contemporaries he considered most cases of what we now know as chronic glaucoma as nothing but amaurosis. The chronic glaucoma of Lawrence and his generation was what we would now consider absolute glaucoma following either an acute or chronic glaucoma. Not until the conception of ocular hypertension and the findings of the ophthalmoscope had been applied could glaucoma simplex become a clinical entity. This group was missed even by von Graefe ${ }^{11}$ who in 1857 spoke of glaucoma of the acute, chronic and secondary types and of amaurosis with excavation of the disc. Not till Donders ${ }^{12}$ (1861) was the unifying conception achieved.

The term acute glaucoma found its way into text books more rapidly than is generally the case with new names: It does not appear in the first edition of Mackenzie's classical book $(1830)^{13}$ though arthritic iritis and glaucoma are fully described. But it finds a place in the second edition, five years later, and in Richard Middlemore's Treatise ${ }^{14}$ published in that same year.

Mackenzie's indebtedness to Lawrence is clearly brought out by a volume in possession of the Ophthalmological Society of the United Kingdom. It is a first edition of Mackenzie's book, interleaved and profusely marked with holograph notes. The book has 
been fully described by R. R. James in an unsigned Annotation..$^{10 .}$ These notes are largely the additional matter of the second edition. One such note refers to acute glaucoma and is shown in the adjoining reproduction. In the second edition this particular marginal note does not appear, though another reference to acute glaucoma does appear for which no manuscript notes are present.

I am indebted to Mr. R. R. James for his information on the history of Mackenzie's book and its holograph notes.

\section{REFERENCES}

1. Hirschberg, J.-Geschichte der Augenheilk. (Graefe-Saemisch), 2nd edition. SS. 276, 3, 4, 291, 280 iv. Leipzig, 1908.

2. Saint-Yves, Ch.-Nouveau traité des yeux, p. 266 . Paris, 1722

3. The fabrick of the eye and the several disorders which obstruct the sight. London, 1758; quoted in-Dictionnaire Encyclopédique des Sciences médicale.. Quatrieme série, Vol. IX, article on glaucoma. Paris, 1883.

4. Arachart.-Quoted in V. Morax, Glaucome et Glaucomateux, p. 7. Paris, 1921.

5. Beer, J.-Die Lehre von den Augenkrankheiten. Vienna, 1813-17

6. Demours, A. P.-Traité des Maladies des Yeux. Tome I, p. 470. Paris, 1818.

7. Weller, C. H.-Die Krankheiten des menschlichen Auges. 3te Auflage, pp. 295 and 474 . Berlin, 1826.

8. Lawrence, W.-Lancet, p. 262, 1826.

9. - Ibid., p. 484.

10. Ibid., Vol. II, p. 711, 1829-30.

11. von Graefe, A.-Ueber die Iridektomie bei Glaucom und ueber den glaucomatösen Process. Arch.f. Ophthal., Bd. III, S. 456, 1857.

12. See Haffiman, J. H. A.-Beiträge zur Kenntniss des Glaukoms. Ibid., Bd. VIII, S. 124,1861 .

13. Mackenzie, $\mathbf{W}-A$ Practical Treatise of the Diseases of the Eye. 2nd edition, p. 826, 1835 . London, 1835.

14. Middlemore, R.-A Treatise of the Diseases of the Eye. Vol. II, p. 12 London, 1835.

15. James, R. R.-Mackenzie's Diseases of the Eye: Author's copy with holograph notes. Brit. Jl. of Ophthal., Vol. VII, p. 376, 1923.

\section{JUBILEE OF \\ THE FRENCH OPHTHALMOLOGICAL SOCIETY}

THE French Ophthalmological Society celebrated the 50th anniversary of its foundation in July and, for the occasion, a large number of guests were invited, representing nearly every country in Europe, and also Egypt and the United States. The guests who accepted the invitation were entertained at the Hotel Majestic where, during the Peace Conference, the British Delegates were lodged. The lounge of the Hotel during the meeting came to resemble a miniature International Congress, with representatives of nearly every European nationality. Among the guests were Professor and Mrs. Wagenmann from Heidelberg, and Professor 